\title{
LETTERS
}

\section{The 2017 Canadian opioid guideline: already time for an overhaul}

The Canadian guideline's ${ }^{1}$ key recommendations are flawed. Based on three small studies on highly select patients, ${ }^{2}$ the guideline recommends tapering for all patients taking dosages at or above $90 \mathrm{mg}$ morphine equivalents daily regardless of their clinical response to the opioid. The guideline does not warn physicians that tapering can put patients at high risk for overdose, because patients will lose tolerance, have distressing withdrawal symptoms and turn to other sources for their opioid.

The guideline does not address treatment of opioid use disorder, even though it is the most serious complication of prescription opioid use and is the major cause of overdose. Buprenorphine/naloxone and methadone treatments have been shown to reduce overdose deaths. ${ }^{3}$ By not discussing these treatments, the guideline encourages physicians to manage opioid addiction through tapering, which is usually ineffective and sometimes dangerous.

We believe that the guideline is contributing to a climate of fear regarding opioid prescribing. Death can occur after rapid tapering or abrupt discontinuation. The guideline needs extensive revision to ensure patient safety; until this is done, the medical community and medical reg- ulators must not use the guideline as the standard for opioid prescribing.

\section{Meldon Kahan MD}

Medical director and addiction physician, Substance Use Service/Addictions Medicine, Women's College Hospital, Toronto, Ont.

\section{Ruth Dubin MD}

Associate professor, Queen's University, Kingston, Ont.; associate professor, Northern Ontario School of Medicine at Lakehead University, Thunder Bay, Ont.

\section{Hance Clarke MD PhD}

Staff anesthesiologist and director of main services, Toronto General Hospital, University Health Network, Toronto, Ont.

Cite as: CMAJ 2018 March 12;190:E300. doi: $10.1503 / \mathrm{cmaj} .68662$

\section{References}

1. Busse JW, Craigie S, Juurlink DN, et al. Guideline for opioid therapy and chronic noncancer pain. CMAJ 2017;189:E659-66.

2. Krumova EK, Bennemann P, Kindler D, et al. Low pain intensity after opioid withdrawal as a first step of a comprehensive pain rehabilitation program predicts long-term nonuse of opioids in chronic noncancer pain. Clin J Pain 2013;29:760-9.

3. Sordo L, Barrio G, Bravo MJ, et al. Mortality risk during and after opioid substitution treatment: systematic review and meta-analysis of cohort studies. BMJ 2017;357:j1550.

Competing interests: Meldon Kahan was a core writer of the 2010 Canadian Guideline for Safe and Effective Use of Opioids for Chronic Non-Cancer Pain. 